for the aerofoil at the blade tip, a possible operating regime is determined.

Mr. Hafner analysed also the forces acting in the plane of rotation of the rotor blade, and pointed out that the two major forces are those due to profile drag of the blade and the components of the lift vector in the plane of rotation. The reduction in the coning angle of the blade is favourable to drag reduction, and by a suitable choice of design para. meters, it is possible to balance the drag variation due to inflow conditions by the variation in profile drag, the result being a general lowering of the level of vibration.

On the question of controls, Mr. Hafner indicated that there is a very great need for simplification, and asserted that four controls represent the minimum number. The possibility of reducing complexity was illustrated by the fact that there are only. twentyseven moving parts in the rotor control mecharism of the Bristol 171.

On the question of stability, Mr. Hafner felt that stability in forward flight is of much greater importance than hovering stability, and that all that is required in the latter direction is that the helicopter should not be unduly unstable. He spoke at length of the problems of the danger zone referred to by previous speakers, and showed some auto-observer records of descent made in the Bristol 171, which indicated the degree of safety of this aircraft. $\mathrm{He}$ closed with some remarks on the question of capital and maintenance costs. He said that these could be reduced by means of good design and that it had been possible for all wearing parts on his machine to be designed for a life of 7,500 hours without great sacrifice in weight.

The last lecturer was Mr. J. Shapiro, who spoke about the Cierva Air Horse. This machine, which is remarkable in many respects, is based on the principle of three lifting rotors. In view of the apparent complication and possible high structure weight of the Air Horse, Mr. Shapiro was faced with the somewhat difficult task of stating its merits which, he claimed, include powerful control in roll and pitch independent of total lift, static stability, dynamic stability in hovering and forward flight, low vibration, ground stability, simple access and, perhaps most important, insensitivity to the position of the centre of gravity when fully loaded. Although these are very desirable, it is difficult to see how the trebling of lifting units and their component parts can have anything other than an adverse effect on the maintenance and utilization of the machine. Since the flying characteristics of the machine have not yet been publicized, it is also difficult to say whether this type of lay-out will achieve all the claims made for it ; but as Mr. Shapiro pointed out, in the absence of quantitative information on the value of the desirable characteristics per hour of maintenance, there is little doubt that many of the adverse criticisms springing to mind may be somewhat unjustified.

The discussion which followed the various speakers was of a high order, and perhaps the most interesting point made was the correlation between the accident rates in the United States and the insurance premiums in England. It seems difficult to appreciate that faulty training or the irresponsibility of pilots in America should adversely affect the insurance rates in Britain. Potential operators in Britain are somewhat concerned over this matter-apart from the fact that at the present time they have no British aircraft to operate. The use of helicopters for crop dusting was referred to in the course of discussion, although no one referred to the success or otherwise of the project. It is possible that much that has been said on this question is wishful thinking, and in the absence of more specific information it would seem that much development is required before success in this field is attained.

HENRY ROBERTS

\section{CONTROL OF EQUILIBRIUM IN THE FLYING INSECT}

THE higher Diptera, 9 mprising such insects as the house-fly, the byow-flies and the hover-flies, have remgrkable $\mathrm{p}$ (1) of controlled flight. The studies of $\mathbf{N} \cdot \mathrm{S}$. J. Follick ${ }^{1}$ on the aerodynamics of diptenf as flight N wed that these insects are inherentl staplofin puch, alterations in attitude being co osted aut matically by a change in the amplitude of the wing beat. There is some suggestion also of inherent stability in the rolling plane, but nothing to indicate stability in yaw. In general aerodynamical terms, the fly probably shows what is known as 'spiral instability'. The lower Diptera, such as the gnats and daddy-long-legs, have long thin abdomens, which must increase their inherent stability. Inherent stability, however, is a definite hindrance to the making of rapid turns. In the higher forms the abdomen becomes short, and aids to flight in the form of organs of equilibrium become more efficient.

G. Fraenkel and J. W. S. Pringle ${ }^{2}$ suggested that such organs of equilibrium are to be found in the oscillating halteres, the modified hind wings of Diptera, which they supposed to act as alternating gyroscopes. Consequently, if the insect is rotated out of the plane of their vibration, lateral shearing forces will be set up in the cuticle at the base and will stimulate the numerous campaniform sense organs that occur there. In ignorance, apparently, of these suggestions, J. Nageotte ${ }^{3,4}$ also put forward the hypothesis that flying Diptera control their equilibrium by the perception of the gyroscopic strains in the halteres.

J. W. S. Pringle ${ }^{5}$ has now presented a detailed study of the gyroscopic mechanism of the halteres. Dynamical analysis of the oscillating system shows that when the fly as a whole is not rotating, the only forces acting on the basal region of the haltere are the primary torques about the main hinge. When it is rotated in any plane not that of the oscillation, gyroscopic torques are set up at the base of the haltere about an axis at right angles to the plane of oscillation. Physical considerations render it improb: able that these gyroscopic torques in the halteres will afford useful information with regard to pitching and rolling rotations. It is only in the yawing plane that the sense organs are likely to give exact information. Flash-photographs of the fly deprived of its halteres confirm that it is, in fact, in that state of spiral instability which is to be expected if ther 3 is inadequate stabilization in the yawing plane.

A re-examination of the sense organs at the base of the haltere, and oscillographic records of impulses in the haltere nerve while the haltere is in a state of natural oscillation, provide good support for these conclusions. When there is no rotation of the body of the fly, impulses are recorded which probably result from excitation of the sense organs of the 'scapal plates' and the 'Hicks papillæ' by the primary forces of oscillation. These organs seem to be excited 
only when the oscillation has reached its maximum. Perhaps they provide a means of limiting the amplitude of oscillation. But when the body of the fly with its halteres oscillating is rotated in yaw or roll, the pattern of impulses in the haltere nerve changes -probably as the result of the campaniform sensilla of the 'basal plate' being excited by the gyroscopic forces. These sense organs have a much higher sensitivity.

Diptera and other insects have campaniform and chordotonal sensilla around the base of their wings. These will presumably detect strains in the wing, and Pringle writes, "one can imagine an evolutionary process, involving a gradual reduction of the wing area and increase of the wing mass, in which the effect of the inertia forces gradually became more important than the aerodynamic forces".

${ }^{1}$ Hollick, F. S. J., Phil. Trans."Roy. Soc., B, 280, 356 (1940)

${ }^{2}$ Fraenkel, G., and Pringle, J. W. S., Nature, 141, 919 (1938).

s Nageotte, J., C.R. Acad. Sci., Paris, 215, 509 (1942).

- Nageotte, J., Arch. Zoo. exp. gen., 83, Notes et Rev. 99 (1944).

sringle, J. W. S., Phil. Trans. Roy. Soc., B, 233, 347 (1948).

$$
1216
$$

\section{LOCATION OF THUNDERSTORMS} BY RAOIQRe

7 HE study of atmosph $r$ disturbances in radio reception began ol before the time when electromagnetic whyowere being applied to practical communication; And from the beginning of the present centuly; various investigators were exploring the possintity of using radio methods for forecasting the rival of thunderstorm conditions. For more thar twenty years, the radio direction-finder with cathode-ray tube indication, first described by $\mathbf{R}$. A. Watson-Watt and J. F. Herd ${ }^{3}$, has been used in the study of the direction of arrival of atmospherics. By the use of a number of such direction-finding stations suitably situated, simultaneous observations can be made on individual atmospherics, and from the bearings obtained the source of the disturbance can be determined. Such a storm-location network has been built up by the Meteorological Office in the British Isles during the past few years, and the regular daily information obtained therefrom has for a long time formed a substantial contribution to the knowledge used in weather forecasting. The general organisation and arrangement of this 'Sferics' service, as it is called, have been described by C. V. Ockenden ${ }^{2}$; and in a paper read before Section $\dot{A}$ of the British Association at Dundee, a general review of the present and possible future techniques for the location of thunderstorms by radio was given by R. L. Smith-Roses.

To meet the demands of the meteorologist for radio direction-finding equipment of the greatest reliability and accuracy, an improved form of the instrument was developed at the National Physical Laboratory, and has been described by F. Adcock and C. Clarkes. The equipment follows the same basic principles described by Watson.Watt and his colleagues, using a pair of crossed-loop receiving aerials connected to twin balanced amplifiers, the outputs from which are connected to the two pairs of plates of the cathode-ray tube. The arrival of an atmospheric causes a line or narrow ellipse to be traced on the screen of this tube in a direction corresponding to that of the source of disturbance at which the atmospheric originated. Various modern improvements in radio and electronic techniques have been incorporated in the present instruments to secure greater reliability, and ease and accuracy of observation. A tube with a long after-glow fluorescent screen is used to enable the observer to make accurate readings on flashes of very short duration. In addition, a brilliance modulator is provided, by means of which only flashes with amplitudes greater than a predetermined value are shown on the tube. This allows the observer to concentrate on the more important flashes. The direction of the disturbances can either be read visually with the aid of a scale and cursor on the tube, or the traces may be photographed as required. In this manner, a thunderstorm area can be located with a high degree of accuracy at ranges up to about $2,500 \mathrm{~km}$.

Following the experimental development described above, the apparatus now in use by the Meteorological Office at four stations in the British Isles has been made by the Plessey Co., Ltd., Ilford, which has given brief details of the sets in a recent Press notice. The receivers operate on a frequency of $12.5 \mathrm{kc} . / \mathrm{s}$. (wave-length $24,000 \mathrm{~m}$.), this being the region of the radio spectrum in which the maximum energy is radiated by a lightning discharge, and also where there is the least likelihood of disturbance from radio transmitting stations. Three observing stations, in Cornwall, Fifeshire and Northern Ireland, are controlled from the fourth at Dunstable, which is the central forecasting station and communication centre of the Meteorological Office. Observations are made twelve times daily, and the resulting information is broadcast over the teleprinter network and by radio to enable aircraft pilots to avoid storm areas, and thus reduce the risk of accidents. The information is also of great importance to the synoptic meteoro. logist in the preparation and study of daily weather charts.

${ }^{2}$ Watson-Watt, R. A., and Herd, J. F., J. Inst. Elec. Eng., 64, 611 (1926).

2 Ockenden, C. V., Met. Mag., 76, 898 (1947)

Smith-Rose, R. L., Advancement of Science, 5, 149 (1948).

Adcock, F., and Clarke, C., J. Inst. Elec. Eng., 94, part 3, 118 (1947).

\section{FORTHCOMING EVENTS 3op}

A (Meetings marked with an asterisk * are open to the public)

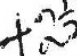

Saturday, January 8

INSTITUTION OF MECHANICAT ENGINEERS, GRADUATES' SECTION (at Storey's fate, St.. James's Park, London, S.W.1), at 3 p.m.-Sir F. Ewart Sifth: "Industrial Research and its Relation to Design and Profiction Monday, January 10

Ro rat Grographical Society (at Kensington Gore, London, S.W.7), at 5.30 p.m.- "How Radar is Used in Navigation" (Sound Films with Introduction by Mr. R. F. Hansford)

Textile Institute, OLdhaM Branch (at the Technical college, Ascroft Street, Oldham), at 7.30 p.m.-Mr. Higgins : "Plastics for Textiles"

\section{Tuesday, January II}

Institution of Chemical ENaINEERs (at the Geological Society, Burlington House, Piccadilly, London, W.1), at 10.15 a.m.-Conference on "Drying".

Brimish Psychologtcal Soctety, Indestriat Section (in Room 105, London School of Hygiene and Tropical Medicine, Keppel Street, London, W.C.1), at 1.10 p.m.-Dr. Philip E. Vernon: "The Structure of Practical Abilities".

ROYAL ANTHROPOLOGICAL INSTITUTE (at 21 Bedford Square, London, W.C.1), at 5 p.m.-Mr. R. G. Lienhardt: "Totemism among the Western Dinka".

INSTITUTION OF ELIECTRICAL ENGINEIRS (joint meeting of the MEASUREMENTS and RADio SRCTIONS, at Savơy Place, Victoria Embankment, London, W.C.2), at 5.30 p.m.-Scientiflc Papers.

INSTITUTION OF NAVAL ARCHTECTS (joint meeting with the INSTIINSTIUTION OF NAVAL ARCHTECTS (joint meeting with the INSTITUTR OF MARINE ENGINEERS, at 85-88 The Minories, London, E.C.3), at 5.30 p.m.-Messts. J. Rhodes, T. H. Arnold and J. R. Rait "Methods, of Non-Destructive Testing of Large Marine Forgings and
Castings". 